This item was submitted to Loughborough's Research Repository by the author.

Items in Figshare are protected by copyright, with all rights reserved, unless otherwise indicated.

\title{
A novel aluminum-carbon nanotubes nanocomposite with doubled strength and preserved electrical conductivity
}

PLEASE CITE THE PUBLISHED VERSION

https://doi.org/10.1007/s12274-021-3284-4

PUBLISHER

Springer

VERSION

AM (Accepted Manuscript)

\section{PUBLISHER STATEMENT}

This is a post-peer-review, pre-copyedit version of an article published in Nano Research. The final authenticated version is available online at: https://doi.org/10.1007/s12274-021-3284-4

\section{LICENCE}

CC BY-NC-ND 4.0

\section{REPOSITORY RECORD}

Zhang, Shuai, Gaoqiang Chen, Timing Qu, Jinquan Wei, Yufan Yan, Qu Liu, Mengran Zhou, et al.. 2021. "A Novel Aluminum-carbon Nanotubes Nanocomposite with Doubled Strength and Preserved Electrical Conductivity". Loughborough University. https://hdl.handle.net/2134/14046752.v1. 


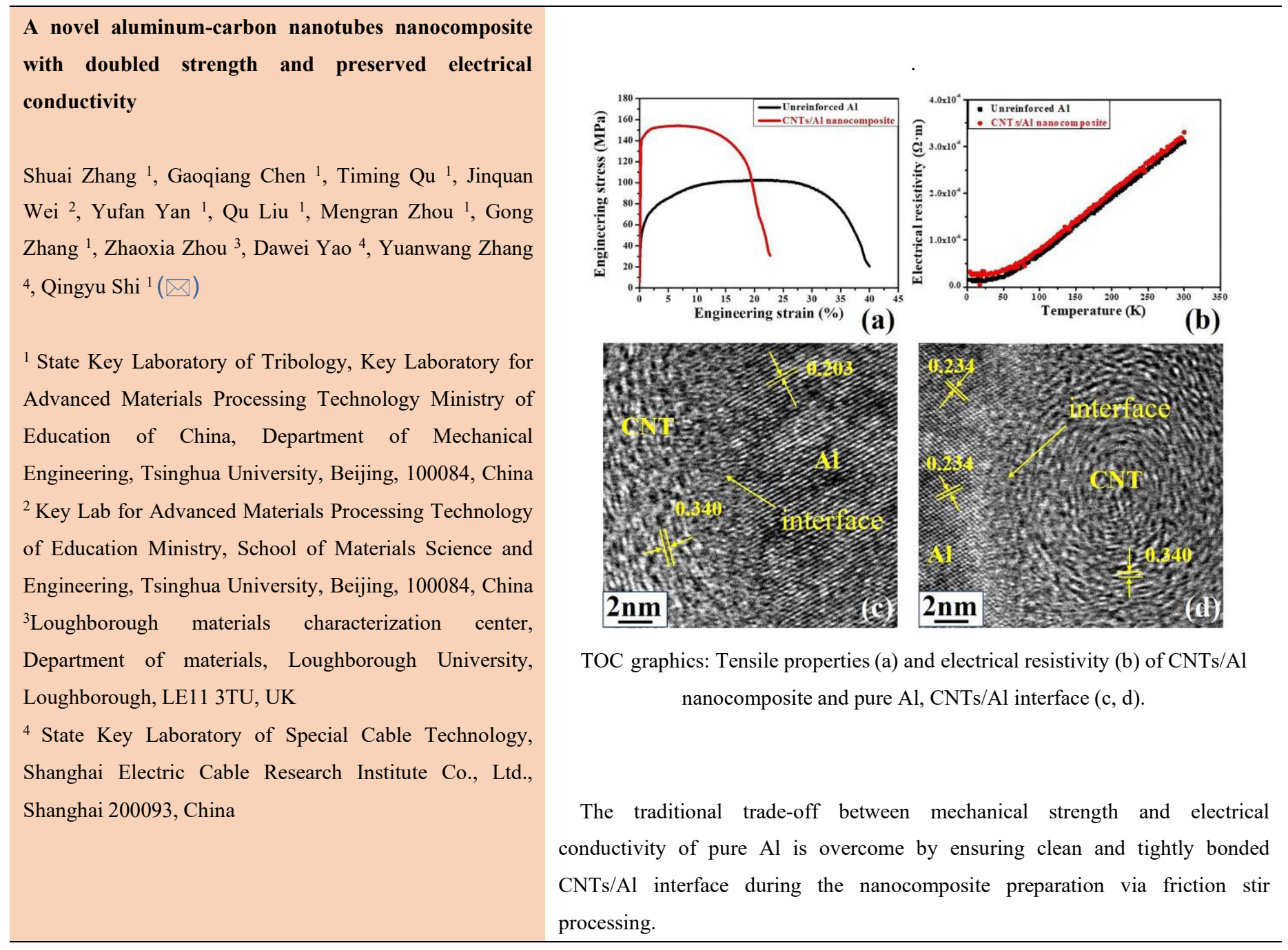





\title{
A novel aluminum-carbon nanotubes nanocomposite with doubled strength and preserved electrical conductivity
}

\author{
Shuai Zhang ${ }^{1}$, Gaoqiang Chen ${ }^{1}$, Timing Qu ${ }^{1}$, Jinquan Wei 2, Yufan Yan ${ }^{1}$, Qu Liu ${ }^{1}$, Mengran Zhou ${ }^{1}$, Gong Zhang ${ }^{1}$, \\ Zhaoxia Zhou ${ }^{3}$, Huan Gao ${ }^{4}$, Dawei Yao ${ }^{4}$, Yuanwang Zhang ${ }^{4}$, Qingyu Shi ${ }^{1}(\bowtie)$ \& Hua Zhang 5 \\ ${ }^{1}$ State Key Laboratory of Tribology, Key Laboratory for Advanced Materials Processing Technology Ministry of Education of China, Department \\ of Mechanical Engineering, Tsinghua University, Beijing, 100084, China \\ ${ }^{2}$ Key Lab for Advanced Materials Processing Technology of Education Ministry, School of Materials Science and Engineering, Tsinghua \\ University, Beijing, 100084, China \\ ${ }^{3}$ Loughborough materials characterization center, Department of materials, Loughborough University, Loughborough, LE11 3TU, UK \\ ${ }^{4}$ State Key Laboratory of Special Cable Technology, Shanghai Electric Cable Research Institute Co., Ltd., Shanghai 200093, China \\ ${ }^{5}$ School of Mechanical Engineering, Beijing Institute of Petrochemical Technology, Beijing 102617, China \\ (C) Tsinghua University Press and Springer-Verlag GmbH Germany, part of Springer Nature 2018 \\ Received: day month year / Revised: day month year / Accepted: day month year (automatically inserted by the publisher)
}

\begin{abstract}
Enhancing the mechanical strength of highly conductive pure metals usually causes significant reduction in their electrical conductivity. For example, introducing phase/matrix interfaces or more grain boundaries, are common and effective methods to strengthen metals. But it simultaneously increases the electron scattering at the interface, thus reducing the electrical conductivity. In this study, we demonstrate that pure aluminum (Al)/carbon nanotubes (CNTs) nanocomposites prepared by friction stir processing have successfully broken through these limitations. The yield strength and tensile strength of Al/CNTs nanocomposites has improved by $104.7 \%$ and $51.8 \%$ compared to pure Al, while the electrical conductivity remained comparable to that of pure Al. To explore the potential mechanisms, the interface between CNTs and Al was examined and characterized by transmission electron microscopy and Raman spectroscopy. Little interfacial reaction compounds were present and no visible physical gaps were observed at CNTs and Al interfaces. We defined it as a clean and tightly bonded interface. Although the quantity of phase interface has increased, the electrical conductivity of the nanocomposite remains approximately unchanged. We attribute the preserved electrical conductivity to the clean and tightly bonded CNTs/Al interface in the nanocomposite.
\end{abstract}

\section{KEYWORDS}

Carbon nanotubes/aluminum nanocomposites, Mechanical properties, Electrical conductivity, Friction stir processing, Interface

\section{Introduction}

For highly conductive pure metals, such as silver (Ag), copper $(\mathrm{Cu})$ and aluminum $(\mathrm{Al})$, strength and electrical conductivity are the two most important properties. Enhancing the strength of these metals without jeopardizing electrical conductivity is of great significance for many applications in electrical and electronic engineering [1-3]. Electrical conductivity is well-known to be very sensitive to the microstructure of metals [2-4]. The microstructure changes that altered the periodic arrangement of lattice significantly would increase the electron scattering and lead to the decrease of electrical conductivity [4]. Generally, the methods of strengthening metal materials, such as alloying, introducing fillers, precipitates or defects, will obviously alter the periodic arrangement of crystal lattice, thus increasing electron scattering. Therefore, enhancing the strength of metal usually comes at the expense of electrical conductivity.

One possible strategy to overcome the above limitations is to fabricate special microstructures in metals, in which electron scattering is significantly weakened while dislocations movement can be effectively hindered [1]. Previous studies have reported that the twin grain boundaries in metal materials have extremely low resistivity, which is about one order of magnitude lower than the traditional large-angle grain boundaries [5-7], and can also effectively hinder the dislocations movements [8, 9]. Such a microstructure in metals would have great potential to improve mechanical properties without loss of electrical conductivity. Lu et al. [1] demonstrated this approach of high-density nano-twin grain boundaries in copper synthesized by a pulsed electrodeposition technique. The strength of copper was increased by about 10 times, while the electrical conductivity remained comparable to that of conventional coarse-grained copper. However, it is difficult to prepare high-density twins in commonly used highly conductive metal materials Ag and Al. If this effect of twin boundary can be extended to heterogeneous phase interface, the strength of pure metal can be improved by significantly increasing the phase interface while without sacrificing its electrical conductivity, which undoubtedly has higher universality. Unfortunately, so far, no relevant reports have been found.

Carbon nanotubes (CNTs) possess high strength and electrical conductivity, and are considered as potential reinforcing fillers to enhance the strength and electrical conductivity of metals [10]. In recent years, many attempts have been made to improve the strength and electrical conductivity of $\mathrm{Ag}, \mathrm{Cu}$ and $\mathrm{Al}$ by

Address correspondence to Qingyu Shi, shqy@mail.tsinghua.edu.cn 
incorporating CNTs using powder metallurgy, electroless deposition methods [11-17]. However, all these attempts concluded that the strength of CNTs/metal nanocomposites improved at the cost of electrical conductivity reduction. The research attributed the reduction of electrical conductivity of CNTs/metal nanocomposites to three main reasons: CNTs/metal interface, micropore and CNTs agglomeration. Among them, the interface between CNTs and metal is the key factor affecting the electrical conductivity of nanocomposites. Chen et al. [15] and Zhou et al. [16] incorporated CNTs into Al matrix by powder metallurgy, which improved mechanical properties but decreased electrical conductivity of Al. The decrease of electrical conductivity of nanocomposites was mainly due to the existence of oxygen-rich $\mathrm{CNTs} / \mathrm{Al}$ interface. The interface itself increased electron scattering, and the existence of oxygen at the interface aggravated the effect of interface on electron scattering, thus reducing the electrical conductivity of materials. Moreover, it is difficult to avoid the introduction of oxygen element in the process of preparing composite materials by powder metallurgy [18]. In addition, micropores in the matrix and pores in CNT agglomeration destroy the periodic arrangement of lattice and enhance electron scattering, thus reducing the electrical conductivity of materials. However, the micropores and aggregation of CNTs in nanocomposites can usually be eliminated by optimizing process parameters $[15,19$, 20].

Friction stir processing (FSP) is a new method for preparing composite materials under solid state conditions, which can effectively minimize the aforementioned defects. Mishra et al. [21] prepared $\mathrm{SiC}$ reinforced 5083Al matrix nanocomposites by FSP for the first time. The results showed that $\mathrm{SiC}$ was homogenously distributed in the matrix, and the hardness of the composite was double that of the matrix. Sun et al. [22] prepared nano SiC particle reinforced magnesium matrix nanocomposites by FSP. The reinforcing phase was uniformly distributed in the matrix and formed a semi-coherent interface with the matrix, and no new compounds were produced at the interface. The tensile strength of the composite was $18.6 \%$ higher than that of the matrix. Liu et al. [20] prepared CNTs/2009Al nanocomposites by combining powder metallurgy with FSP. After FSP, the dispersion of CNTs in the nanocomposite was obviously improved, CNTs were dispersed singly and formed an intimate interface with the matrix. Previous studies [22, 23-25] have shown that FSP is effective to incorporate the reinforcing phase into metal matrix, in which the reinforcing phase can be uniformly dispersed, and without introducing impurity at the interface.

Based on the above analysis, we suspect that if tightly bonded CNTs/metals interfaces with absence of impurity compounds can be formed in the nanocomposites, the adverse effects of interfaces on the electrical conductivity will be greatly minimized. Then it is possible to obtain the composite materials with the electrical conductivity comparable to or even higher than that of the metal matrix. Therefore, FSP method was selected in this study to prepare the CNTs/Al nanocomposites. The electrical conductivity and strength of the composite material were measured. The characteristics of CNT/Al interface formed under FSP were observed and analyzed. The effect of the CNTs/Al interface on the strength and electrical conductivity of CNTs/Al nanocomposites will be discussed.

\section{Experimental section}

\subsection{Materials}

In this study, commercial pure Al, AA1060(Al:99.6 wt.\%), was used as metal matrix and multi-walled CNTs were used as reinforcing phase. The morphology of the original CNTs was characterized by transmission electron microscopy (TEM) and shown in Fig. 1a. Due to the large Van der Waals force, the original CNTs are entangled with each other. The average diameter of CNTs is about $12.1 \mathrm{~nm}$. The number of CNTs walls is about 20, as shown in Fig. 1 b.

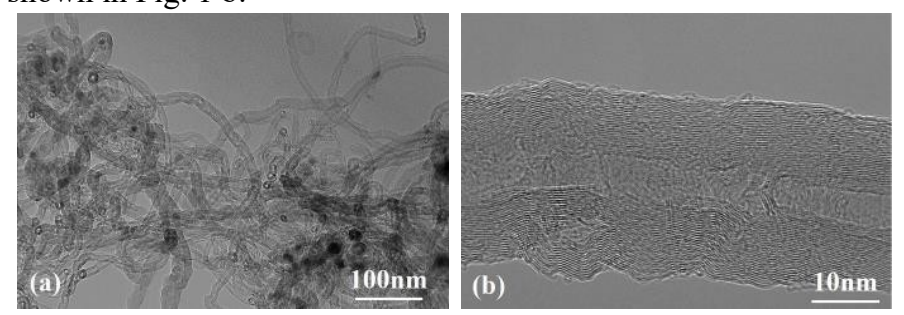

Figure 1 (a) Morphology of the as-received CNTs by TEM. (b)High resolution TEM structure of CNTs.

\subsection{Fabrication of CNT/Al nanocomposites by FSP}

The FSP had three steps in the fabrication process. The first step was to prepare the base material. Three solid plates of AA1060 were used, which were to be mounted top, middle and bottom plates respectively before FSP, as shown in Fig. 2. The top and bottom plates were identical $300 \times 100 \times 3 \mathrm{~mm}$ (length $\times$ width $\times$ thickness). The middle plate was $300 \times 100 \times 2 \mathrm{~mm}$. Then five slots $(150 \times 2 \times 2 \mathrm{~mm}$, length $\times$ width $\times$ depth $)$ with an interval distance of $5 \mathrm{~mm}$ between the adjacent slots were machined on the middle plate. The plates were polished to remove the oxide and the containments on the surfaces.

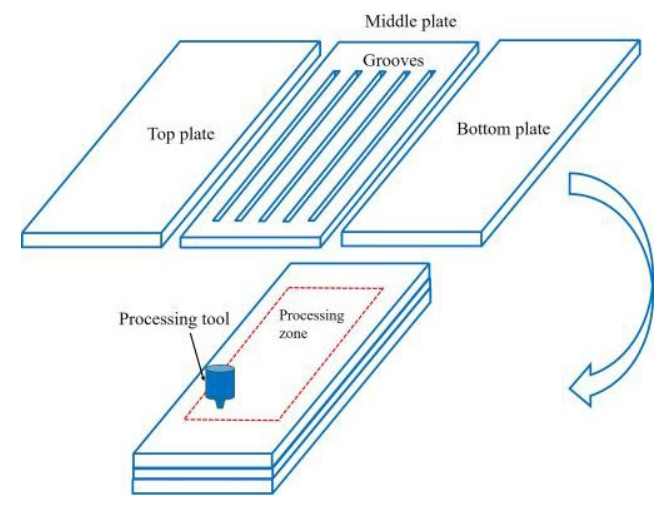

Figure 2 Schematic diagram of the multi-pass FSP.

The second step was to fill these grooves with CNTs. The middle plate was placed above the bottom plate. The grooves on the middle plate were filled with CNTs. Then the top plate was placed above the middle plate before FSP to cover the CNTs. The third step was to blend CNTs into Al matrix. A rotating nonconsume tool made of nickel-based alloys gradually plunged into $\mathrm{Al}$ and transferred through the region containing the slots. The tool consisted of cylinder shoulder and threaded pin. The shoulder was $20 \mathrm{~mm}$ in diameter. The diameter of the pin was $4 \mathrm{~mm}$ at topand $6 \mathrm{~mm}$ at bottom. The pin length was $5.0 \mathrm{~mm}$. A right-hand thread was machined on the pin. During the processing process, the tilt angle between the tool axis and the surface normal of the top plate was $2.5^{\circ}$. The rotational speed and travel speed were $950 \mathrm{rpm}$ and $30 \mathrm{~mm} / \mathrm{min}$ respectively. Partially overlapped three-pass FSP with an offset of $3 \mathrm{~mm}$ between the adjacent passes was carried out 
in this study. For comparison, pure Al underwent the same processing conditions as a control. It was named as unreinforced $\mathrm{Al}$. The volume fraction of CNTs was calculated to be $3.2 \mathrm{Vol} \%$ based on the density of CNTs/Al nanocomposite (Archimedes' principle) and calibrated with the unreinforced $\mathrm{Al}$ and as-received commercial pure Al.

\subsection{Characterization of the microstructure}

Samples were cut from the processing zone for microstructure characterization. Raman spectroscopy with a laser of wavelength of $532 \mathrm{~nm}$ was employed to identify the presence of CNTs in the nanocomposites and characterize the structural integrity of CNTs. The interfacial bonding characteristics between CNTs and Al were investigated by transmission electron microscopy (TEM, JEOL JEM-2100F). Ion thinning machine was used to fabricate the TEM samples. CNTs distribution was investigated by using Raman spectroscopy and TEM. Fracture surfaces of tensile specimens were examined by using a field emission scanning electron microscope (FE-SEM, Quanta 200FEG).

\subsection{Measurement of mechanical properties and electrical conductivity}

The strength and elongation of nanocomposites were measured by a single column bench-top electronic universal testing machine (Zwick Z2.5 TH). The gauge length, width and thickness of the samples were $5 \mathrm{~mm}, 1.5 \mathrm{~mm}$ and $0.8 \mathrm{~mm}$ respectively. The tensile test was carried out at room temperature at a strain rate of $1.0 \times 10^{-}$ ${ }^{3} \mathrm{~s}^{-1}$. The electrical conductivity of nanocomposites and pure Al was measured over the temperature range from $4 \mathrm{~K}$ to $300 \mathrm{~K}$ using Quantum Design PPMS. The size of electrical conductivity test samples was $10 \times 1.8 \times 0.2 \mathrm{~mm}$. The size of samples was measured using micrometer and optical microscope. Before the electrical conductivity measurement, the sample surface was mirror-polished to minimize the uncertainty of electrical

conductivity measurement caused by surface conditions and contaminations.

\section{Results and discussion}

\subsection{Electrical and mechanical properties of CNTs/Al nanocomposite}

Fig. 3 shows the temperature dependence of electrical resistivity in the temperature range of $4 \mathrm{~K}$ to $300 \mathrm{~K}$ for $\mathrm{CNTs} / \mathrm{Al}$ nanocomposite and unreinforced Al. The electrical resistivity of the $\mathrm{CNTs} / \mathrm{Al}$ nanocomposite is very close to that of unreinforced $\mathrm{Al}$ over the entire temperature range. This result shows that although large number of $\mathrm{CNTs} / \mathrm{Al}$ interfaces (CNTs: 3.2 vol.\%) are incorporated into $\mathrm{Al}$ matrix by FSP, the electrical resistivity of CNTs/Al nanocomposite remains comparable to that of unreinforced Al. Within the range of $100 \mathrm{k}$ to $300 \mathrm{k}$, the electrical resistivity of these two materials decreases linearly with temperature, which is associated with the scattering mechanisms induced by lattice vibration. When the temperature is lower than $100 \mathrm{~K}$, the electrical resistivity decreases nonlinearly with temperature, associated with the electron scattering mechanism induced by lattice defects [4].

The mechanical properties of the unreinforced $\mathrm{Al}$ and $\mathrm{CNTs} / \mathrm{Al}$ nanocomposites were evaluated by tensile test. The stress-strain curves of unreinforced $\mathrm{Al}$ and CNTs/Al nanocomposite are shown in Fig.4. It can be found that with the addition of CNTs, the yield strength and tensile strength of $\mathrm{Al}$ are significantly enhanced. The yield strength and tensile strength of CNTs/Al nanocomposite are $104.7 \%$ and $51.8 \%$ higher than those of unreinforced $\mathrm{Al}$ respectively. Detailed information on the mechanical properties of unreinforced $\mathrm{Al}$ and $\mathrm{CNTs} / \mathrm{Al}$ is summarized in Table 1.

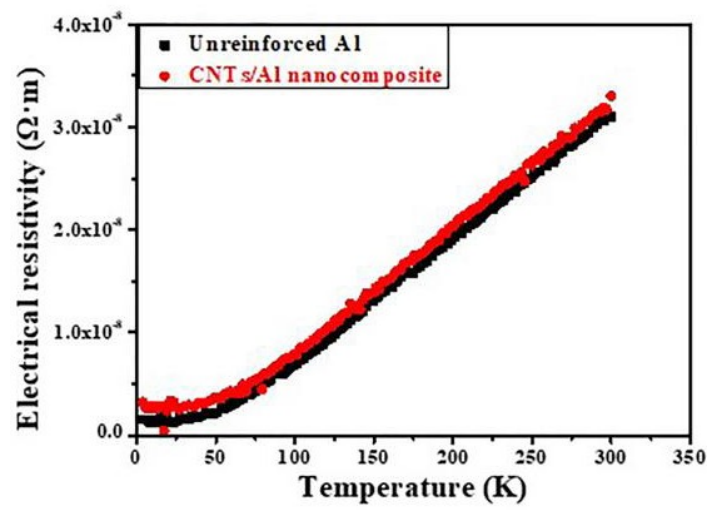

Figure 3 The measured temperature dependence of electrical resistivity for $\mathrm{CNTs} / \mathrm{Al}$ nanocomposite and unreinforced $\mathrm{Al}$.

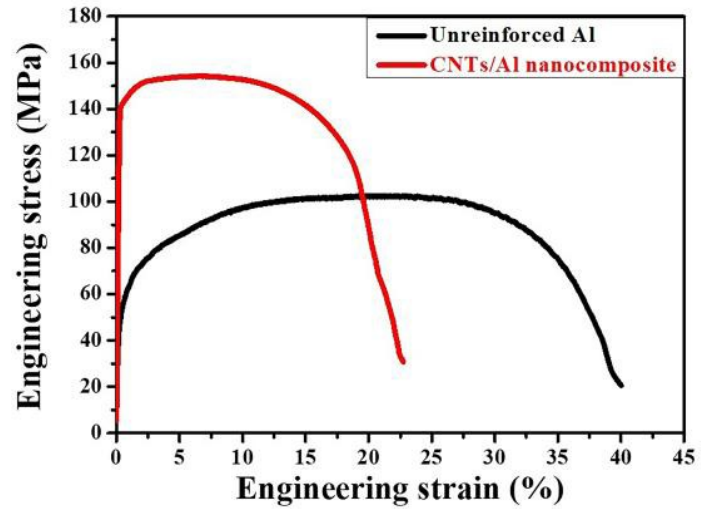

Figure 4 Stress-strain curves of unreinforced $\mathrm{Al}$ and $\mathrm{CNTs} / \mathrm{Al}$ nanocomposite.

Table1 Mechanical properties and electrical conductivity of the unreinforced $\mathrm{Al}$ and CNTs/Al nanocomposite.

\begin{tabular}{|c|c|c|c|}
\hline Sample & $\begin{array}{c}\text { Yield strength } \\
(\mathrm{MPa})\end{array}$ & $\begin{array}{c}\text { Tensile strength } \\
(\mathrm{MPa})\end{array}$ & $\begin{array}{c}\text { Total elongation } \\
(\%)\end{array}$ \\
\hline $\operatorname{lnf}$ & $64.0 \pm 10.6$ & $101.3 \pm 1.8$ & $39.5 \pm 2.1$ \\
\hline $\mathrm{NT}$ & $131.0 \pm 10.3$ & $153.8 \pm 2.6$ & $24.0 \pm 3.1$ \\
\hline
\end{tabular}

Fig. 5 shows typical SEM micrographs of fracture morphology of unreinforced $\mathrm{Al}$ and CNTs/Al nanocomposites. A large number of submicron sized dimples were observed on the fracture surface, indicating that both the unreinforced $\mathrm{Al}$ and CNTs/Al nanocomposites show typical ductile fracture. The results are consistent with the high elongation values of the materials obtained by tensile tests. Some short rods were found on the fractures of CNTs/Al nanocomposites (Fig. 5b). Their diameters were found to be tens of nanometers, which is on the order of the diameter of CNTs used in this study. Most of the rods were present in the dimples. Therefore, it is inferred that these short rods are likely to be CNTs, as reported in the previous literatures [14-16]. Due to the electron beam matter interaction volume of SEM technique, it is impossible to ascertain that it is CNTs from the perspective of composition. In the future, more sensitive equipment with high detection capability is needed to clarify it as CNTs $[26,27]$. 


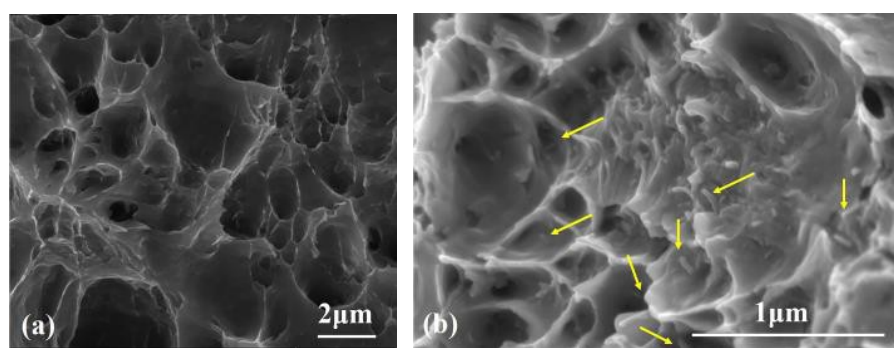

Figure 5 SEM micrographs of the fracture surfaces. (a) Unreinforced Al. (b) $\mathrm{CNT} / \mathrm{Al}$ nanocomposite.

\subsection{Structure characterization of CNTs in CNTs/Al nanocomposite}

Raman spectroscopy was used to identify the existence of CNTs in Al matrix and characterize the structural characteristics of CNTs after FSP. It can be clearly seen from Fig. 6 that the Raman spectra obtained from the CNTs/Al nanocomposites shows two representative peaks at $1349 \mathrm{~cm}-1$ and $1601 \mathrm{~cm}-1$, corresponding to the $\mathrm{D}(1341 \mathrm{~cm}-1)$ and $\mathrm{G}(1576 \mathrm{~cm}-1)$ peaks of the original CNTs, which confirms that the CNTs were successfully introduced into the Al matrix by FSP. Compared with the original CNTs, the positions of $\mathrm{D}$ band and $\mathrm{G}$ band in CNTs/Al nanocomposites move to a higher value, which is attributed to the structural changes of CNTs [28] caused by FSP. The intensity ratio of D band to G band is usually used to characterize the structural damage degree of CNTs [29, 30]. In this study, the intensity ratio (1.13) of D band and $\mathrm{G}$ band of CNTs in nanocomposites is slightly higher than that of original CNTs (1.09), which may be due to the slight increase of defect density caused by the temperature and high strain during FSP. No peaks were observed at $485 \mathrm{~cm}-1,680 \mathrm{~cm}-1$ and $840 \mathrm{~cm}-1$ which belong to $\mathrm{Al}_{4} \mathrm{C}_{3}[29,31]$ in the nanocomposite, indicating that $\mathrm{Al}_{4} \mathrm{C}_{3}$ is absent in nanocomposites or the amount of $\mathrm{Al}_{4} \mathrm{C}_{3}$ in nanocomposites is barely to be detected.

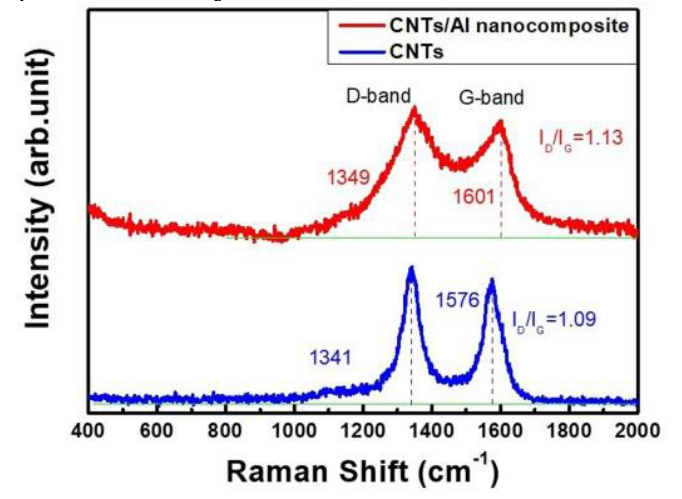

Figure 6 Raman spectra of CNTs and CNTs/Al nanocomposite.

\subsection{The distribution of CNTs investigated using Raman spectroscopy and TEM}

Raman spectroscopy was also used to study the distribution of CNTs in macro-scale. The detection spot size of Raman spectrum was estimated as $1.25 \mu \mathrm{m}$. The location for Raman analysis is shown in Fig. 7a, and the result is shown in Fig. 7b. It was found that CNTs were present at almost all positions on the cross-section of nanocomposite, which indicates that CNTs was well dispersed in the Al matrix on the macro scale. However, it can also be seen from Fig. 7 that the distribution of CNTs does have a certain degree of inhomogeneity. This may be due to insufficient local area mixing during large-scale stir during the preparation of bulk composite materials, so the characteristic peaks of CNTs in some local areas are weak. However, it can also be seen from the Raman results that the characteristic peaks of CNTs can be clearly observed in a large area. The samples used for microstructure analysis and performance testing in this study are taken from regions with pronounced characteristic peaks_of

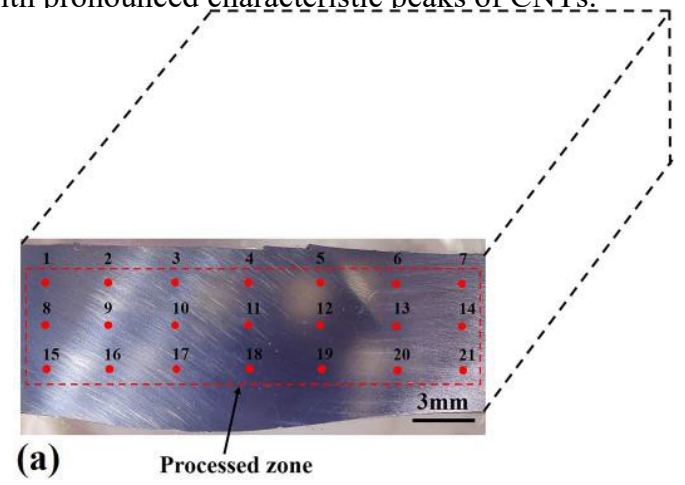

(a) Processed zone

(b)

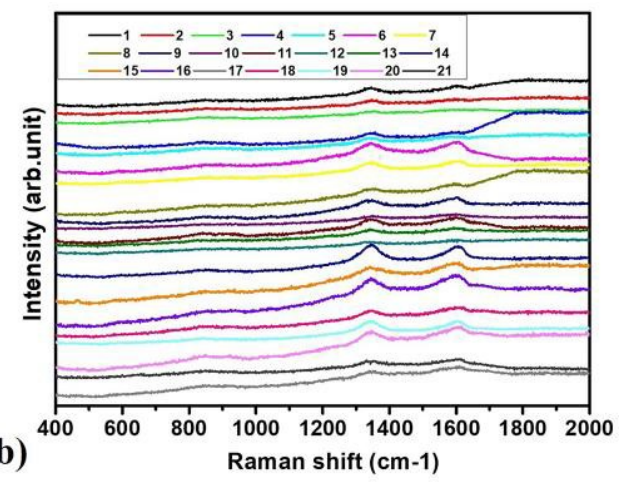

Figure 7 Diagram of locations for Raman analysis (a) and Raman spectra of $\mathrm{CNTs} / \mathrm{Al}$ nanocomposite at different locations (b).

In this study, the dispersion of CNTs at micro-scale was further analyzed by TEM. Five positions were randomly selected on the cross section of the composite material for TEM analysis, as shown in Fig. 8. Fig. 9a-e are representative TEM images of the CNTs distribution in Al matrix. It is evident that singular CNTs are uniformly distributed throughout the Al matrix. In addition, CNTs still retain their typical characteristic structure after FSP thermalmechanical processing, and exist stably in Al matrix. There are some black particles with diameters of hundreds of nanometers, composition analysis by EDS suggested they were Fe-, Si-rich. Since commercial grade pure Al plates is used as matrix, the existence of a small amount of inclusions and precipitates is inevitable $[32,33]$.

The TEM results suggest that singular CNTs homogenously distributed in the Al matrix in nano-scale. This is because during the FSP process, high energy is generated between the processing tool and $\mathrm{Al}$ and inside the $\mathrm{Al}$ matrix, which makes the Al matrix soften when heated [34]. Plastic flow occurs to the softened Al matrix under the mechanical stirring action of processing tool and drives the surrounding CNTs to flow together, so that the Al matrix and CNTs are able to mix. The high strain and shear stress produced by the softened Al matrix in the flow process [35, 36] will effectively break the CNTs agglomeration, which also results in breakage of the CNTs, hence smaller aspect ratios, and easier to mix further. Eventually, the CNTs are homogenously and in singular form distributed in the Al matrix. In the meantime, because the mixing of Al matrix and CNTs in the FSP process is carried out in an approximately closed metal cavity formed by the 
processing tool and the surrounding cold metal matrix, and the metal material is always in a solid state, the generation of micropores in the nanocomposite and the introduction of impurity such as oxides are inhibited. The adverse effects on the electrical conductivity of the CNTs/Al nanocomposite caused by the manufacturing process is avoided.

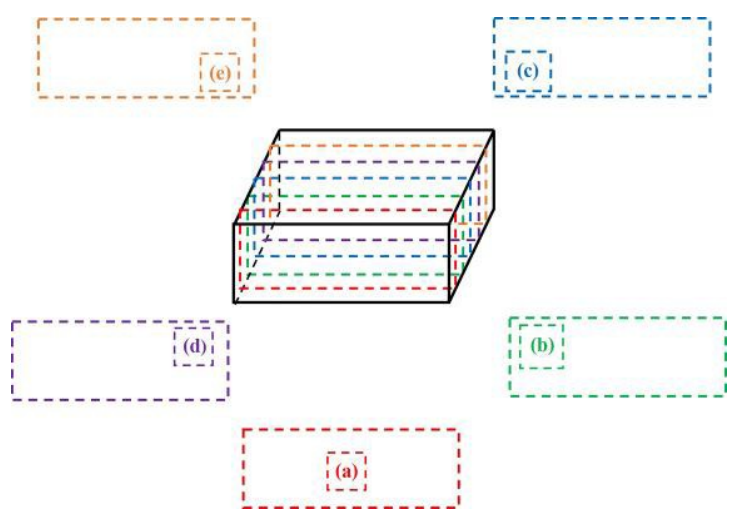

Figure 8 Diagram of locations for TEM sampling.
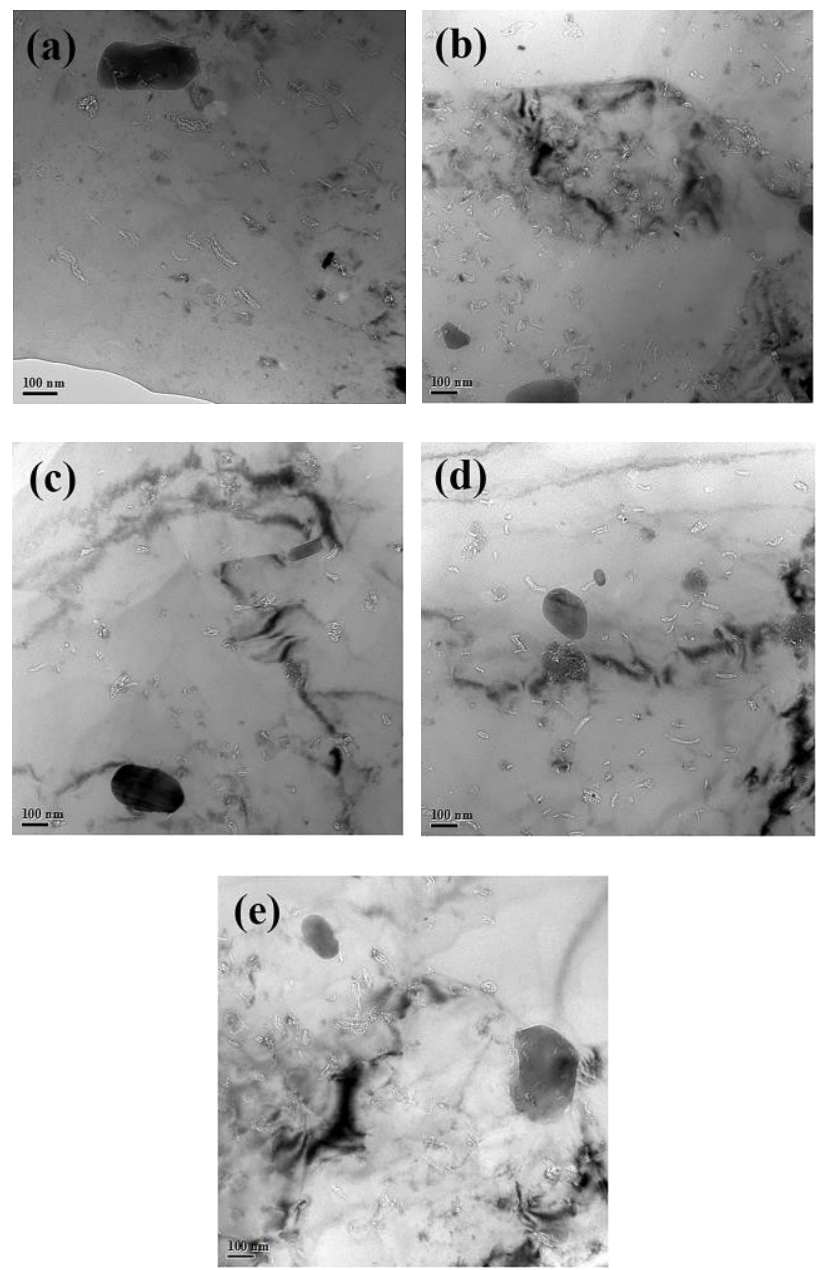

Figure 9 CNTs dispersion at micro-scale. (a-e) CNTs dispersion at different locations.

\subsection{The effect of CNTs on the electrical conductivity and strength of the nanocomposite}

The electrical resistance of metals originates from the electrons scattering during directional movement. Scattering of electrons can be divided into two parts: scattering of electrons by lattice vibration and scattering of electrons by impurity atoms, dislocations, vacancies and interfaces [4, 37]. Compared with the structure of pure Al, CNTs are homogenously distributed in the nanocomposite prepared in this study. The introduction of CNTs into Al matrix will bring two competitive factors. On one hand, the ultra-high electrical conductivity of CNTs is preferable to improve the electrical conductivity of $\mathrm{Al}[10]$. On the other hand, the existence of $\mathrm{CNTs} / \mathrm{Al}$ interface will increase electron scattering, thus reducing the electrical conductivity of Al. Among them, the strength of electron scattering at the CNTs/Al interface with different bonding status is different, which leads to CNTs/Al nanocomposites with different electrical conductivity.

The factors that affect the electron scattering at the CNTs/Al interface mainly include the interfacial impurity [38] and the interfacial gap [39]. $\mathrm{Al}_{4} \mathrm{C}_{3}$ is not conductive at room temperature. If $\mathrm{Al}_{4} \mathrm{C}_{3}$ forms at the interface, it will significantly increase the scattering effect of the interface on electrons and reduce the electrical conductivity of the nanocomposite. The research results of Chen et al. [15] and Zhou et al. [16] showed that the oxygen element enriched at the interface between $\mathrm{Al}$ and CNTs could also enhance the electron scattering at the interface and reduce the electrical conductivity of the material. On the other hand, Matsuda et al. [40] calculated the contact resistance between different metals and CNTs by density functional theory (DFT) and green's function method, and found that a smaller interfacial gap between CNTs and metals lead to a smaller contact resistance. Naeemi et al. [41] and Dong et al. [42] also reported that the contact resistance between CNTs and metals could be significantly reduced through the localized Joule heating method, which was attributed to the decrease of interfacial gap between CNTs and metal induced by localized Joule heating [43].

Fig. 10 are high-resolution TEM images of the interface between CNTs and $\mathrm{Al}$ in CNTs/Al nanocomposites prepared in this study. Fig.10 (a) shows the interface between side walls of a CNT and Al matrix, and Fig.10 (b) shows the interface between end cap of a CNT and Al matrix. The distance between the two adjacent walls of CNTs is about $0.34 \mathrm{~nm}$. It can be clearly seen from Fig. 10 that both the side walls and the end of the CNTs form clean interfacial bonding with the Al matrix. CNTs and Al matrix are tightly bonded, and interfacial gap is less than the distance between atomic planes of Al matrix and the distance between tube walls of CNTs. This is because the high temperature and high-pressure conditions in the FSP process will promote the formation of tight bonding between the softened Al matrix and CNTs without gaps [44-46]. On the other hand, impurity elements are hardly introduced in the FSP process. Therefore, clean CNTs/Al interface has formed under FSP condition. The analysis of microstructure in this study shows that under FSP conditions, Al and CNTs form a clean and tightly bonded $\mathrm{CNTs} / \mathrm{Al}$ interface. Based on the above discussion, this clean and tightly bonded interface can significantly reduce the scattering effect of the CNTs/Al interface on electrons. Therefore, we believe that the reason why the electrical conductivity of the $\mathrm{CNTs} / \mathrm{Al}$ nanocomposite prepared in this study is comparable to that of pure $\mathrm{Al}$ is due to the formation of this clean and tightly bonded interface in the CNTs/Al nanocomposite. 


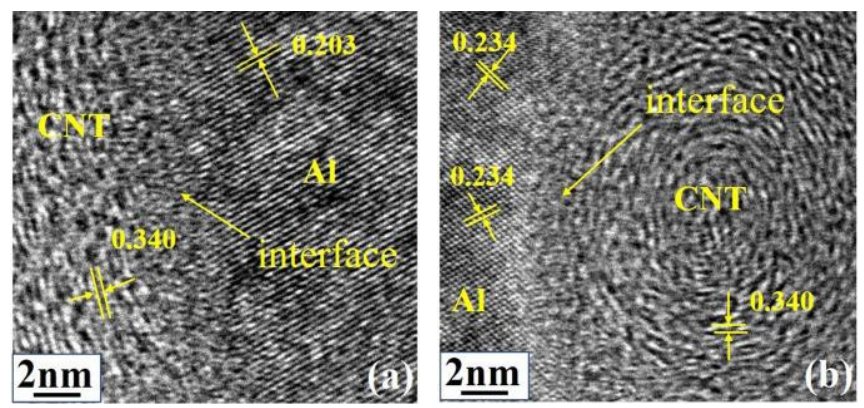

Figure 10 HRTEM images of interface characteristics. (a) An interface between a CNT's side walls and Al. (b) An interface between the end cap of a CNT and Al.

The microstructure induced by CNTs is the reason for the strength improvement of $\mathrm{CNTs} / \mathrm{Al}$ nanocomposite. Firstly, the incorporation of CNTs will inhibit the grain growth of Al matrix. The grain size of the CNTs /Al nanocomposite is refined, so the strength is improved [47]. Secondly, when the CNTs/Al nanocomposite bears the load, the load can be transferred from $\mathrm{Al}$ to CNTs through the tightly bonded CNTs/Al interface, so the strength is improved [48]. Thirdly, when the CNTs/Al nanocomposite is plastically deformed, CNTs will hinder the movement of dislocations, thus improving the strength [49]. These three strengthening mechanism models $[50,51]$ are used to predict the strength of CNTs / Al nanocomposite. The result shows that the predicted strength of CNTs / Al nanocomposite is $138.5 \mathrm{MPa}$, which is in good agreement with the experimental measured value of 131.0MPa. Therefore, the strength improvement in CNTs/Al nanocomposite can be attributed to the synergistic effect of fine grain refining, Orowan looping mechanism and load transfer mechanism.

At present, metallurgical methods are commonly used to prepare CNTs reinforced metal matrix nanocomposites. It can be seen from the existing literatures [11-17] that metal matrix nanocomposite materials with high CNTs content can be obtained through metallurgical methods, and the effect of strengthening the mechanical properties is significant. However, the process of preparing CNTs reinforced metal matrix nanocomposite materials by metallurgy is usually accompanied by metal oxidation, chemical reactions between CNTs and metal matrix, resulting in excessive chemical reactions at interface. These factors may have no obvious influence on the mechanical properties, but they will reduce the electrical properties of CNTs/metal nanocomposites. Compared with metallurgical methods, FSP is a solid-state processing method, which can avoid the unfavorable factors on electrical conductivity during the preparation of composite materials. The clean and tightly bonded CNTs/Al interface shown in this study can be formed under the thermo-mechanical condition during FSP, and this interface is likely to be an important reason for improving the mechanical properties without reducing the electrical properties. However, the amount of CNTs added in this study is only about 3.2 vol.\%, which is probably the main reason why the mechanical properties of nanocomposite materials prepared in this study are not significantly improved. Compared with the literature [20], Liu et al. combined powder metallurgy and FSP to prepare CNTs reinforced 2009 Al-based nanocomposites for the first time. The volume fraction of CNTs in the nanocomposite was increased to about $4.5 \%$ by powder metallurgy, and then FSP was used to realize the homogenization of CNTs. Then the composite material with significantly improved mechanical properties was obtained. However, increasing the content of CNTs through powder metallurgy also brings negative effects. The microstructure analysis results in the literature show that carbides are formed inside the composite material, which may sacrifice part of the electrical properties. Although the results of electrical properties are not given in the literature [20], the electrical conductivity of CNTs reinforced metal matrix nanocomposite prepared by powder metallurgy [11, 13-17] prove this from the side. This study aims to achieve a coordinated improvement of mechanical-electrical performance. One of the most important aspects is to increase the content of CNTs while avoiding the generation of poor bonded interfaces. In the future, we need to improve the preparation method to further increase the strength and electrical conductivity of Al.

\section{Conclusions}

This study has demonstrated an exceptional phenomenon of enhancing the strength of CNTs/Al nanocomposite while retaining the electrical conductivity comparable to that of pure $\mathrm{Al}$, which is attributed to the formation of clean and tightly bonded CNTs/Al interfaces in the nanocomposite. It could be observed that no compound was formed between $\mathrm{Al}$ and CNTs, and there was no visible physical gap at these interfaces. The clean and tightly bonded CNTs/Al interfaces can effectively hinder the dislocations movements and the electron scattering at these interfaces is significantly weakened. As a result, the yield strength and tensile strength of Al/CNTs nanocomposites are improved by $104.7 \%$ and $51.8 \%$ compared with pure $\mathrm{Al}$, while the electrical conductivity remains comparable to that of pure Al. Therefore, this study may provide new insight into break through the trade-off tendency between enhancing strength and electrical conductivity of metals.

\section{References}

[1] Lu, L; Shen, Y. F; Chen, X. H; Qian, L. H; Lu, K. Ultrahigh strength and high electrical conductivity in copper. Science. 2004, 304, 422-426.

[2] Valiev, R. Z; Murashkin, M. Y; Sabirov, I. A nanostructural design to produce high-strength $\mathrm{Al}$ alloys with enhanced electrical conductivity. Scripta. Mater. 2014, 76, 13-16.

[3] Cui, X. L; Wu, Y. Y; Zhang, G. J; Liu, Y. B; Liu, X. F. Study on the improvement of electrical conductivity and mechanical properties of low

alloying electrical aluminum alloys. Compos. Part. B-Eng. 2017, 110, 381-387.

[4]Desai, P. D; James, H. M; Ho, C. Y. Electrical Resistivity of Aluminum and Manganese. J. Phys Chem. Ref. Data. 1984, 13, 1131-1172.

[5] Sutton, A. P; Balluffi, R. W. Interfaces in Crystalline Materials. Clarendon, Oxford, 1995.

[6] Zhou, B. H; Xu, Y; Wang, S; Zhou, G. H; Xia, K. An ab initio investigation on boundary resistance for metallic grains. Solid. State. Commun. 2010, 150, 1422-1424.

[7] Kino, T; Endo, T; Kawata, S. Deviations from Matthiessen's Rule of the Electrical Resistivity of Dislocations in Aluminum. J. Phys. Soc. Jpn. 1974, 36, 698-705.

[8] Christian, J.W; Mahajan, S. Deformation twinning. Prog. Mater. Sci. 1995, 39, 1-157.

[9] Shen, Y. F; Lu, L; Lu, Q. H; Jin, Z. H; Lu, K. Tensile properties of copper with nano-scale twins. Scripta. Mater. 2005, 52, 989-994.

[10] Hjortstam, O; Isberg, P; Söderholm, S; Dai, H. Can we achieve ultra -low resistivity in carbon nanotube-based metal composites?. Appl. Phys. A-Mater. 2004, 78, 1175-1179.

[11] Feng, Y; Yuan, H. L; Zhang, M. Fabrication and properties of silver-matrix 
nanocomposites reinforced by carbon nanotubes. Mater. Charact. 2005, 55, 211-218.

[12] Daoush, W. M; Lim, B. K; Mo, C. B; Nam, D. H; Hong, S. H. Electrical and mechanical properties of carbon nanotube reinforced $\mathrm{Cu}$ nanocomposites fabricated by electroless deposition process. Mat. Sci. Eng. A-Struct. 2009, 513, 247-253.

[13] Uddin, S. M; Mahmud, T; Wolf, C; Glanz, C; Kolaric, I; Volkmer, C; Höller, H; Wienecke, U; Roth, S; Fecht, H. Effect of size and shape of metal particles to improve hardness and electrical properties of carbon nanotube reinforced $\mathrm{Cu}$ and $\mathrm{Cu}$ alloy nanocomposites. Compos. Sci. Technol. 2010, 70, 2253-2257.

[14]Liu, Z. Y; Xiao, B. L; Wang, W. G; Ma, Z. Y. Tensile strength and electrical conductivity of carbon nanotube reinforced $\mathrm{Al}$ matrix nanocomposites fabricated by powder metallurgy combined with friction stir processing. $J$. Mater. Sci. Technol. 2014, 30, 649-655.

[15] Chen, B; Li, S. F; Imai, H; Jia, L; Umeda, J; Takahashi, M; Kondoh, K. Carbon nanotube induced microstructural characteristics in powder metallurgy Al matrix nanocomposites and their effects on mechanical and conductive properties. J. Alloy. Compd. 2015, 651, 608-615.

[16] Zhou, W. W; Yamamoto, G; Fan, Y; Kwon, H; Hashida, T; Kawasaki, A. In-situ characterization of interfacial shear strength in multi-walled carbon nanotube reinforced Al matrix nanocomposites. Carbon. 2016, 106, 37-47. [17]Xu, C. L; Wei, B. Q; Ma, R. Z; Liang, J; Ma, X. K; Wu, D. H. Fabrication of Al-carbon nanotube nanocomposites and their electrical properties. Carbon. 1999, 37, 855-858.

[18] Ibrahim, I. A; Mohamed, F. A; Lavernia, E. J. Particulate reinforced metal matrix composites — a review. J. Mater. Sci. 1991, 26, 1137-1156.

[19] Liu, Z. Y; Xu, S. J; Xiao, B. L; Xue, P; Wang, W. G; Ma, Z. Y. Effect of ball-milling time on mechanical properties of carbon nanotubes reinforced aluminum matrix composites. Compos. Part. A-Appl. S. 2012, 43, 2161-2168. [20]Liu, Z. Y; Xiao, B. L; Wang, W. G; Ma, Z. Y. Singly dispersed carbon nanotube/aluminum composites fabricated by powder metallurgy combined with friction stir processing. Carbon. 2012, 50, 1843-1852.

[21] Mishra, R. S; Ma, Z. Y; Charit, I. Friction stir processing: a novel technique for fabrication of surface composite. Mat. Sci. Eng. A-Struct. 2003, 341, 307310 .

[22] Sun, K; Shi, Q. Y; Sun, Y. J; Chen, G. Q. Microstructure and mechanical property of nano-SiCp reinforced high strength $\mathrm{Mg}$ bulk composites produced by friction stir processing. Mat. Sci. Eng. A-Struct. 2012, 547, 32-37.

[23] Cao, X; Shi, Q. Y; Liu, D; Feng, Z. L; Liu, Q; Chen, G. Q. Fabrication of in situ carbon fiber/aluminum nanocomposites via friction stir processing: Evaluation of microstructural, mechanical and tribological behaviors. Compos. Part. B-Eng. 2018, 139, 97-105.

[24] Izadi, H, Gerlich, A. P. Distribution and stability of carbon nanotubes during multi-pass friction stir processing of carbon nanotube/aluminum nanocomposites. Carbon. 2012, 50, 4744-4749.

[25] Liu, Q; Ke, L. M; Liu, F. C; Huang, C. P; Xing, L. Microstructure and mechanical property of multi-walled carbon nanotubes reinforced aluminum matrix composites fabricated by friction stir processing. Mater. Design. 2013, $45,343-348$.

[26] Zhou, Z. X; Rainforth, W. M; Luo, Q; Hovsepian, P. Eh; Ojeda, J. J; Romero-Gonzalez, M. E. Wear and friction of TiAlN/VN coatings against $\mathrm{A} 12 \mathrm{O} 3$ in air at room and elevated temperatures. Acta. Mater. 2010, 58, 29122925.

[27] Zhou, Z. X; Rainforth, W. M; Tan, C. C; Zeng, P; Ojeda, J. J; RomeroGonzalez, M. E; Hovsepian, P. Eh. The role of the tribofilm and roll-like debris in the wear of nanoscale nitride PVD coatings. Wear. 2007, 263,1328-1334.

[28] Choi, H; Shin, J. H; Min, B; Park, J; Bae, D. Reinforcing effects of carbon nanotubes in structural aluminum matrix nanocomposites. J. Mater. Res. 2009, 24, 2610-2616.

[29] Chen, B; Shen, J; Ye, X; Imai, H; Umeda, J; Takahashi, M; Kondoh, K.
Solid-state interfacial reaction and load transfer efficiency in carbon nanotubes (CNTs)-reinforced Al matrix composites. Carbon. 2017, 114,198-208.

[30]Chen, B; Li, S. F; Imai, H; Jia, L; Umeda, J; Takahashi, M; Kondoh, K. An approach for homogeneous carbon nanotube dispersion in Al matrix composites. Mater. Design. 2015, 72, 1-8.

[31]Sun, Y; Cui, H; Gong, L; Chen, J; Shen, P. K; Wang, C. X. Field nanoemitter: one-dimension Al4C3 ceramics. Nanoscale. 2011, 3, 2978-2982. [32]Raptis, D; Seferlis, A. K; Mylona, V; Politis, C; Lianos, P. Electrochemical hydrogen and electricity production by using anodes made of commercial aluminum. Int. J. Hydrogen. Energ. 2019, 44, 1359-1365.

[33]Ma, J. J; Li, W. H; Wang, G. X; Li, Y. Q; Ren, F. Z; Xiong, Y. Influences of L-Cysteine/Zinc Oxide Additive on the Electrochemical Behavior of Pure Aluminum in Alkaline Solution. J. Electrochem. Soc. 2018, 165, A266-A272. [34]Su, H; Wu, C. S; Pittner, A; Rethmeier, M. Thermal energy generation and distribution in friction stir welding of aluminum alloys. Energy. 2014, 77,720731.

[35] Liu, X. C; Sun, Y. F; Nagira, T; Ushioda, K; Fujii, H. Experimental evaluation of strain and strain rate during rapid cooling friction stir welding of pure copper. Sci. Technol. Weld. Joi. 2019, 24, 352-359.

[36] Colegrove, P. A; Shercliff, H. R. CFD modelling of friction stir welding of thick plate 7449 aluminium alloy. Sci. Technol. Weld. Joi. 2006, 11, 429-441.

[37]Alley, P; Serin, B. Deviations from Matthiessen's Rule in Aluminum, Tin, and Copper Alloys. Phys. Rev. 1959, 116, 334-338.

[38] Cao, M; Luo, Y. Z; Xie, Y. Q; Tan, Z. Q; Fan, G. L; Guo, Q; Su, Y. S; Li, Z. Q; Xiong, D. B. The Influence of Interface Structure on the Electrical Conductivity of Graphene Embedded in Aluminum Matrix. Adv. Mater. Interfaces. 2019, 6, 1900468.

[39] Wilhite, P; Vyas, A. A; Tan, J; Tan, J; Yamada, T; Wang, P; Park, J; Yang, C. Y. Metal-nanocarbon contacts. Semicond. Sci. Technol. 2014, 29, 054006.

[40]Matsuda, Y; Deng, W. Q; Goddard, W. A. Contact Resistance Properties between Nanotubes and Various Metals from Quantum Mechanics. J. Phys.

Chem. C. 2007, 111, 11113-11116.

[41] Naeemi, A; Meindl, J. D. Carbon nanotube interconnects. Annu. Rev. Mater. Res. 2009, 39, 255-275.

[42] Dong, L. F; Youkey, S; Bush, J; Jiao, J. Effects of local Joule heating on the reduction of contact resistance between carbon nanotubes and metal electrodes. J. Appl. Phys. 2007, 101, 024320.

[43] Yamada, T; Saito, T; Suzuki, M; Wilhite, P; Sun, X. H; Akhavantafti, N; Fabris, D; Yang, C. Y. Tunneling between carbon nanofiber and gold electrodes. J. Appl. Phys. 2010, 107, 044304.

[44] Chen, G. Q; Feng, Z. L; Chen, J; Liu, L; Li, H; Liu, Q; Zhang, S; Cao, X; Zhang, G; Shi, Q. Y. Analytical approach for describing the collapse of surface asperities under compressive stress during rapid solid state bonding. Scripta. Mater. 2017, 128, 41-44.

[45] Wu, J. Q; Lee, C. C. Low-pressure solid-state bonding technology using fine-grained silver foils for high-temperature electronics. J. Mater. Sci. 2018, 53, 2618-2630.

[46] Wu, J. Q; Huo, Y. J; Lee, C. C. Direct Ag-Ag bonding by in-situ reduction of surface oxides for advanced chip-package interconnection. Materialia. 2018, 4, 417-422.

[47] Nam, D. H; Cha, S. I; Lim, B. K; Park, H. M; Han, D. S; Hong, S. H. Synergistic strengthening by load transfer mechanism and grain refinement of CNT/Al-Cu composites. Carbon. 2012, 50, 2417-2423.

[48] Kelly, A; Tyson, W. R. Tensile properties of fibre-reinforced metals: copper/tungsten and copper/molybdenum. J. Mech. Phys. Solids. 1965, 13, 329350.

[49] George, R; Kashyap, K. T; Rahul, R; Yamdagni, S. Strengthening in carbon nanotube/aluminium (CNT/Al) composites. Scripta. Mater. 2005, 53, 11591163 .

[50] Chen, B; Kondoh, K; Imai, H; Umeda, J; Takahashi, M. Simultaneously enhancing strength and ductility of carbon nanotube/ aluminum composites by 
improving bonding conditions. Scripta. Mater. 2016, 113, 158-162.

[51] Park, J. G; Keum, D. H; Lee, Y. H. Strengthening mechanisms in carbon nanotube-reinforced aluminum composites. Carbon. 2015, 95, 690-698.

[52]Ryu, H. J; Cha, S. I; Hong, S. H. Generalized shear-lag model for load transfer in SiC/Almetal-matrix composites. J. Mater. Res. 2003, 18, 2851-2858. 
